\title{
Self-Construal and Its Implications for Marketing
}

\author{
Kun Gai \\ School of Management, Jinan University, Guangzhou, China \\ Email: galerav@sina.com
}

How to cite this paper: Gai, K. (2018) Self-Construal and Its Implications for Marketing. Open Journal of Social Sciences, 6, 269-286.

https://doi.org/10.4236/jss.2018.65020

Received: May 3, 2018

Accepted: May 26, 2018

Published: May 29, 2018

Copyright $\odot 2018$ by author and Scientific Research Publishing Inc. This work is licensed under the Creative Commons Attribution International License (CC BY 4.0).

http://creativecommons.org/licenses/by/4.0/

\begin{abstract}
Self-construal is the concept of the individual's understanding of the relationship between the self and others. Different self-construals have different effects on the individual's behavior. This article compares the differences in individual consumption behaviors of individuals with different self construals, and analyzes the cognitive factors that produce such differences. Finally, it provides the application methods of self-construal in marketing practice.
\end{abstract}

\section{Keywords}

Self-Construal, Consumer Behavior, Marketing

\section{Introduction}

Self-construal was first proposed by Markus and Kitayama in 1991 about people's understanding of the relationship between self and others. According to the different perceptions and opinions of individuals on their relationship with others, self-construal can be divided into independent self-construal and interdependent self-construal. If an individual perceives him-or-herself as someone other than another person, such as, I am a person with an independent identity [1], then the individual has an independent self-construal; if the individual perceives him-or-herself as a continuation of another, or others perceive their continuance as "I am part of other people", then the individual has an interdependent self-construal. The initial study of self-construal was based on the western independent culture. The West has a slang saying that "the squeaky wheel gets engine oil", emphasizing publicity and expressing one's own ideas. Marcus believed that the influence of constructs on the self, others, and the relationship between the self and other individuals is more pronounced than that of previous studies. Moreover, this influence also shows clearly in different cultures. Markus 
also compared the difference between self-independence and self-interdependence [1]. In Western culture, there is a belief in the uniqueness of human beings. The norm of this culture is that individuals should become individuals who are independent of others and discover and express their own unique personalities [2] [3]. This cultural norm requires people to construct themselves as such an individual. His behavior must first comply with his own inner thoughts, emotions, and actions, rather than referring to the thoughts, emotions, and actions of others [1]. But individuals who are independent self-construal also have to respond to the social environment. This response stems from the need for strategic choices to express the inner ways of the self. The existence of others or the social environment is first of all reflected as the source of the evaluation or verification of the inner core of the self. In contrast, many non-Western cultures emphasize the basic connection between people. The norm in this culture is to maintain the interdependent relationship between people. Interdependent self-construal individuals see themselves as part of the social relationships around them and can be aware that their actions are determined by the perceptions, emotions, and behaviors of others they perceive. When an individual is embedded in an appropriate social relationship, he is the most meaningful and complete. This kind of trait is particularly prominent in East Asian culture. Lebra's research found that when Japanese people are in a connected environment, they feel that they are the most complete [1]. The intrinsic qualities of self-consisting individuals are also unique, but in many cases they play a minor role in regulating external behavior. On the contrary, people's self-knowledge and self-consciousness dominate people's behavior. This self-control of the inner qualities constitutes the core of the cultural ideal-become mature. It's the point that separates the independent self-construal and interdependent self-construal. Although different types of self-construal are embedded in different cultures, self-construal is not static but dynamic.

As early as 1986, Liu's research showed that China's educational environment contains procedural knowledge that allows individuals to get along with others [4], which affects individuals with different constructs. Triandis and Trafimow have verified a series of situational factors. Regardless of whether an individual is a member of a group or a member of a group, the self-construal of the individual's public image is highlighted when providing collectivist clues. When individualistic clues are provided, the individual is concerned, private self-evaluation will be highlighted. Through the meta-analysis of the initiation of two self-construal constructs and the analysis of subsequent regulatory effects, the conclusion of the contextual model supporting the culture is concluded. Self-construal is not static but dynamic in the cross-cultural differences. Independent or interdependent performance is both permanent and instant.

The concept of self-construal has been paid attention by scholars since its introduction. Based on Markus's research, Brewer proposed that independent self-construal and dependent self-construal should exist on each individual, and 
divide self-construal into individual self that defines self from their own uniqueness, from self and intimacy. The relationship of others defines the relationship between the self and the definition of self collective self from the relationship between themselves and the subordinate groups [5]. In the subsequent studies, Cross et al. further subdivided the dependence self-construal, group-dependent self-construal and relationship-dependent self-construal. The former is a collectivist culture. The individuals in the latter group are representative of women in North American culture [6]. In addition, Brewer proposed on the basis of empirical evidence that self-construal is easily influenced and activated by the situation. From the perspective of stability, self-construal is divided into special-type self-construal and situation-based self-construal [5].

In empirical studies, trait self-construals are measured through self-reporters, and contextual self-constructions are activated through activation. There are three main measurement scales for common trait self-construal, Singelis' self-construction scale, which is a two-dimensional seven-point scale, but the reliability and validity of the scale are low [7]; on the basis of Singelis, Gudykunst et al. developed independent and interdependent self-construal scales. Although the reliability and validity have been significantly improved, this scale has drawn a number of relevant measurement tools in cultural contexts [8]. This applies only to cross-cultural studies and does not apply to research within culture; in addition, Cross prepared a relational-interdependent self-construal scale, which is used only for the measurement of dependent self-construals of relational tendencies and has an ideal distinction Validity and Convergence Validity [6]. Situational self-construal is often used as an independent variable in empirical research and needs to be initiated through experimental interventions. Commonly used methods can be divided into the following categories. In the instructional language initiation method, a sentence that can evoke a certain self-construal of the subject is added to the experimental instruction to be read. For example, "everyone in your university is an independent individual" or "you are a college student. A group of children" etc. [9] [10]; story initiation method, let the subject read a short story to be told, the first half of the story is the same, the latter half represents a different self-construal, such as "someone is running a game if Success can win a bonus" or "someone's team is playing a game, if successful, the team can win a bonus" [11] [12] [13] [14]. The task initiation method allows the subject to complete a task and initiate individual self-construal through the manipulation of whether the quality of completion of the task affects the individual or affects the group in which the individual lives [15] [16] [17].

Self-construal as a psychological concept of self provides a new perspective for the scholars to explore the individual differences in mind and behavior. Scholars discovered in the study that there is a connection between self-construal and cognitive style. Individuals with independent self-construal show more field independence, and individuals with dependent self-construal show more field-dependence [18] [19]. Self-construal also influences the object of social 
comparison. Gardner found in the study that independent self-construal individuals prefer to compare with strangers. Dependent self-construal individuals prefer to compare with acquaintances. Gardner also found that self-construal also has an impact on interpersonal behavior [20]. Independent self-construal individuals are more considerate of the satisfaction of self-needs in decision-making, and keep distances from others in social communication [21]. When interacting with strangers, they have less imitation behavior and have less interest in decision-making of others [22] [23]. In contrast, dependent self-construal individuals take more consideration of the needs of others in decision-making, do not feel close to others in social interactions, generate more imitations in stranger interactions, and are willing to help others do Make decisions. The study of self-construal also penetrated into the field of consumer decision-making. Since the economic and social development, various products have been overwhelming. In order to increase the popularity of products among consumers, companies have tried various marketing methods to study consumer behavior. Has become the most practical and instructive topic, but also put forward a new perspective and requirements for self-construction research.

At present, there is a wealth of research on the impact of self-construal on consumer behavior in foreign countries. It has great guiding significance for accurate marketing, improving product awareness and sales. This article will sort out relevant research in recent years, explaining the impact of self-construal on consumer behavior, and how companies should use this series of research to improve their marketing effectiveness in practice.

\section{The Influence of Different Self-Construal on Consumer Behavior}

At present, the influence of self-construal on consumer behavior mainly focuses on the actual consumer behaviors of self-construal individuals (such as impulsive consumption and symbol consumption), different types of advertisements (such as advertising appeals, advertising forms), and brand attitudes (such as The response to brand damage) etc. This section comprehensively reviews the relevant literature in the above aspects, and elaborates and summarizes the effects of different self-construals on consumer behavior.

\subsection{Different Self-Construal Individuals Have Differences in Actual Consumption Behavior}

Individuals with different self-construal follow different choice bases when choosing consumer goods. With regard to differences in choices made, recent research has mainly embodied impulsive consumption and symbolic consumption.

In recent years, the individual's impulsive consumption behavior has become a research hotspot. Although not all impulsive consumer behavior is necessarily problematic, impulsive consumption is usually associated with a series of nega- 
tive traits (immature and poor value systems) and negative consequences (financial issues, low self-esteem, and dissatisfaction after shopping, etc.) are linked together [24] [25]. Impulsive consumption refers to the sudden, spontaneous, unplanned desire to purchase a certain product. Impulse consumption is a kind of irrational consumption. Consumers do not measure and analyze their own behavior in terms of maximization of utility, diminishing marginal effect, and income constraints during the consumption process. Scholars generally believe that impulsive consumption is the conflict and contradiction between the desire to buy and the will to resist desire [26]. The recent research on the willpower to resist greed focuses on the ability of willpower. Aspect (self-control), and its relationship to impulsive shopping behavior [27]. Zhang and Shrum focus attention on the self-construal of the active component of willpower, in order to verify how self-construal can affect the individual's impulse shopping behavior by influencing the activation of willpower [28].

In a 2002 study, Kacen and Lee demonstrated the relationship between independentism and collectivism and impulsive consumer behavior [29]. Studies have shown that members of an independent society exhibit more impulsive consumer behavior, while members of a collectivistic society have a stronger incentive to suppress their impulses. Studies in the United States, Australia, Hong Kong, Singapore, Malaysia, and other countries and regions have found that both the independent cultural background and independent self-construal are positively related to consumer impulse behaviors. The study by Zhang and Shrum also confirmed the cultural differences in impulse consumer behavior [28]. In addition, they further verified the performance of individuals with different self-construal on impulse consumer behavior. Studies have shown that both the trait-specific self-construal that an individual possesses, and the contextual self-construction that is evoked by laboratory methods, all have the same tendency. That is, individuals with independent self-construal are more independent than reciprocal self-construals. The individual who reads has a more positive attitude towards beer consumption. In addition, peer presence is considered to be one of the factors affecting impulse consumption [30] [31]. The presence of others in the interdependent self-construal may be more significant than the independent self-construal. The impact of individual reading is even more pronounced. It also makes interdependent self-construal individuals have more incentives to suppress their desire to buy. And peers will increase interdependent self Construct the individual's tendency to suppress impulsiveness, but if the ability to control willpower of interdependent self-construal is reduced by other methods, then the effect of peer presence is no longer significant. Interdependent self-construal individuals and independent self-construal individuals The performance was similar in the presence of peers.

Symbol consumption refers to the individual's choice of goods in the consumption process. The basis for selecting goods is not the actual quality of the goods, but the symbolic attributes of the goods. People obtain the factors from 
the symbolic resources to construct, express, and consolidate their identity [32]. Lee and Kacen pointed out in the study that the emphasis on uniqueness and autonomy of independent individuals prompted them to tend to pay more attention to costumes with self-symbolic meaning, and that interdependent individuals emphasized acceptance [33]. And adapting, there is a stronger preference for the symbol of friendly relations with clothing. However, in subsequent studies, their results have not been fully confirmed.

First, it is clear that independent self-construal individuals emphasize uniqueness and self-expression, which drives individuals to seek diversification [34], and have a strong desire for more product combinations [35]. At the same time, uniqueness and self-expression can be obtained by consuming expensive or even extravagant items that cannot be afforded by others [36]. One of the typical products that can reflect this uniqueness is the latest fashion. It has novelty, uniqueness, and high-price labels that can show its status and prestige. It also means that individuals have the financial resources to update their wardrobe at any time. Clark and Millan and Reynolds have verified that independent self-construal individuals may prefer the symbol of clothing status [37] [38]. However, there are also scholars whose research results are in contrast to Kastanakis and Balabanis who found a negative correlation between independent constructs and status symbol consumption [39]. As for the relationship between interdependent self-construal and symbolic consumption, scholars also gave guesses and verifications. According to the characteristics of interpersonal self-construction in pursuit of harmony and friendly interpersonal relationships, some scholars speculate that interdependent self-construal individuals do not have too many statuses to symbolize the propensity to consume. Lee and Kacen reported in their studies that whether individuals are impulsive or planned consumers, the basis for individual choice of goods for interdependent self-construal is related to the friendly relationship within the collective. Independent self-construal individuals have no such phenomenon in both scenes [33]. Research by Millan and Reynolds shows that there is no significant correlation between interdependent self-construal and preference for clothing status symbol [38]. However, a commercial data shows that Japan and China, two countries that clearly have a collectivist culture, are among the top performers in the luxury goods consumption list. The desire to connect with family and friends and social pressure from meeting others' expectations and keeping their face behind appear to be one of the drivers of increasing luxury spending in these regions [40]. Based on the findings and contradictions of the merchants, the following conclusions are drawn through empirical research. Independent individuals, when constructing, expressing, and enhancing their unique identity, have more use of self and identity symbols and hedonistic resources [41]. The status and distinction from others (avoiding the purchase of clothing that important people already own) is their main driving force for frequent visits to new stores and consumption. There is no special preference for the friendly attributes 
of the self-constructed individuals in the interdependent self-construal clothing. It does not play an intermediary role in the relationship between self-construal and actual purchase behavior. Interdependent self-construal individuals do not have clear characteristics in their actual purchase behavior. On the one hand, interdependent self-construal individuals uphold a modest attitude that is integrated with the collective and will not be able to express their own distinctiveness. Preference, so the price of goods that express self-ability is not considered too much by such individuals, and on the other hand, in order to be able to counter social pressures such as face, interdependent self-construal individuals value luxury attributes of goods.

In summary, independent self-construal individuals are influenced by the characteristics of the uniqueness of self-expression. They will show more impulsivity and enjoyment in consumption. They value the status symbol of goods and tend to choose to express their status and capabilities. A product that is different from the characteristics of others. Interdependent self-construal individuals are influenced by the characteristics of their harmonious and harmonious social environment. In order not to break social norms, they show less impulsivity and hedonicity in consumption, especially when there are peers present. The tendency of one's impulsive type is even more pronounced. Even if it is the purchase of luxury goods, it is to resist social pressure and get along well with others in the social environment.

\subsection{Different Self-Construal Individuals Have Different Preferences for Advertising Appeals}

Advertising is one of the important means of corporate marketing. The persuasive effect on consumers is one of the criteria for evaluating whether an advertisement is effective. If the appeal expressed in the advertisement is consistent with or similar to the audience, the persuasive effect of the advertisement will be higher. Han and Shavitt, Zhang and Gelb have verified the persuasive effects of different appeals at the cultural level through experiments, and found that advertisements emphasizing personal interests are more effective in persuading Americans, and advertisements emphasizing collective interests are more persuasive to the Chinese [42] [43]. This cultural difference exactly corresponds to the difference in self-construal under different cultural backgrounds. Therefore, scholars speculate that this may be due to differences in self-construal of individuals.

As early as 1982, Sirgy proposed the theory of consistency between self-image and product image. If the brand clues involved in the advertisement are consistent with the individual's self-image, then consumers prefer the brand promoted by the advertisement [44]. Hong and Zinkhan's research also yielded results that are consistent with the above theories [45]. They found that if the public appeal is consistent with the consumer's self-concept (such as introversion and extroversion) when the brand is represented, the consumer will have a more positive 
attitude towards the brand. After further research, scholars have discovered the relationship between self-construal and preference for different types of advertising. Wang and Mowen's study found that individuals with interdependent self-construal tend to prefer advertisements that emphasize communication and connect topics, whereas individuals with independent self-construals tend to emphasize advertisements with independent themes [46]. Wang also studied the influence of self-construal on the preferences of broad appeal on the cultural and gender levels, and further analyzed which dimensions of self-construal play a role in this influence. The subjects in the experiment were from several universities in the United States and China. The experiment was divided into two stages. The first stage consisted of the participants completing the self-constructed questionnaire to determine their characteristics in each dimension. After two to three weeks, the second stage was followed by an advertisement pamphlet randomly assigned to the same type of watch, an advertisement for independent appeal, and the slogan "XX watch makes you unique art". This type of advertisement is a collective appeal. The slogan is "XX watch, emotional reminder". As a result, it was found that advertisements for collective appeals led to more active brand attitudes for Chinese participants than independent advertisements. At the same time, female participants in different cultures also showed more preference for advertisements for collective appeals. Through analysis of different dimensions, Wang found that although self-construal plays a significant mediating role in cultural preferences and gender differences' preference for wide appeals, in two situations, the different dimensions of self-construal. In terms of cultural differences, the dimensions of the relationship between self and others have a greater influence on self-orientation dimensions, while on the gender lev$\mathrm{el}$, the dependence dimension has a greater influence.

In addition, scholars also discovered the influence of self-construal on imagination advertising strategies. Imaginative advertising is currently the most common form of advertising. It aims to increase the incentive for advertising by stimulating consumers to experience the process of experiencing products [47] [48] [49] [50]. Imaginative advertising has a significant impact on improving the willingness to purchase experiential products [51]. Based on this theory, Self-construction happens to be an individual's perception of self, so imagine Advertising should have different effects on individuals who have different self-construal. The experimental results show that imaginative advertising will significantly increase the individual's willingness to buy self-constructed individuals, but the impact on interdependent self-construal individuals is not so significant.

Through the above studies, we can find that for different types of self-construal related, the appeal and type of advertisement will affect its persuasiveness. Individuals with self-construal of independent type prefer to those who emphasize independentism, and imagine that advertisements have greater persuasion; while interdependent self-construal individuals prefer those advertise- 
ments that emphasize social emotional connection, and imagine advertisements on them. The persuasive effect does not have a significant persuasive effect on individuals who conceive themselves.

\subsection{Different Self-Construal Individuals Have Different Attitudes towards Brand Transgressions}

Brand transgressions refers to the fact that certain behaviors of the company have undermined the explicit or implicit rules that govern the relationship between consumers and brands [52], resulting in a decrease in consumers' evaluation of the brand. Brand damage may be due to a problem with the quality of the product, such as a cell phone battery explosion or an automobile accelerator pedal failure. It may also be that the brand's attitudes and beliefs are not in line with public expectations. For example, when the quality is a problem, the brand is Courage to admit mistakes or shirk responsibility. The consumption of products is reduced. Therefore, for companies, understanding what actions to take when a brand is damaged can allow consumers to forgive brands, and it is crucial to win consumers' hearts and loyalty. Brand transgressions can cause consumers to react differently. Generally speaking, these reactions depend on two factors: consumers' perception of the controllability of brand transgressions and how they relate to the brand. When individuals think that the brand is innocent and the transgression is not controlled by the company, their performance will not be so negative [53] [54]; moreover, if the consumer and the brand are Positive relationships, they will not be too pessimistic in the face of brand transgressions [55] [56]. In the face of brand transgressions, consumers do not consider these two factors at the same time. Different individuals will have different tendencies. That is, some individuals will tend to decide whether to forgive the brand transgressions event by determining whether the damage is controllable. Some individuals tend to decide by the degree of their own relationship with the brand. Scholars have found that self-construal is one of the factors that influence the attribution of individuals. Cross and Madson pointed out that interdependent individuals like to attribute the damage event through the degree of relationship between themselves and the brand [57]. The closer the relationship with the brand, the more easily the interdependent individual can attribute the damage event beyond the control of the enterprise. External factors. Collectivism sees the destruction as a threat to the harmony of people and society, and believes that forgiveness is the way to maintain and rebuild balance. In contrast, independent individuals attribute the damage based on the damage event itself and the brand's remedial action. If the damage event is uncontrollable and the brand takes a positive remedial action, then the individual is more likely to attribute the damage to the outside world. Factors make it easier to forgive brands. Collectivism considers the event of destruction as a threat to interpersonal and social harmony. Forgiveness is the way to maintain and rebuild balance. In the independent culture, individuals with independent self-construal see 
damage as an unfair fracture [58]. They hope that companies can make some kind of moves to redress this injustice. Studies at the cultural level have demonstrated that during the assessment, Americans are more concerned with the controllability of damage events, and the Japanese are focusing on their relationship with the destructors [59].

Through laboratory research, Sinha and Lu explored the strength of the relationship between consumers and brands, damage is controllable, and the relationship between the three types of self-construal. The experiment used a 2 * $2 * 2$ test room design. Subjects first completed self-construal manipulation tasks and then listed health drink companies they were familiar with or unfamiliar with. Then, the participants were faced with the circumstances in which the listed companies encountered product failures (both controllable and uncontrollable) and reported on the possibility of forgiveness of the incident, the possibility of verbally spreading negative news, and controllability. Perception. The follow-up experiment also asked participants to predict their expectations of the relationship between brands and their expectations of fairness. As a result, it has been found that independent individuals will be more independent in their testing of brand damage incidents, and do not rely on intimacy with the relationship between brands, but instead uphold the principle of fairness and decide whether to forgive the brand depending on whether the damage is reliable or whether the follow-up is fair. Interdependent self-construal individuals rely on the relationship with the brand to decide whether to forgive the damage event, but when the relationship with the brand is strong, interdependent self-construal is more tolerant to uncontrollable damage than controllable damage [60]. Therefore, scholars speculate that in the face of such situations, interdependent self-construal individuals will not only consider controllability factors, but also consider factors related to the relationship between brands. Although no conclusions have been given at present, we believe that individuals who believe in interdependent self-construal will consider two factors when judging whether to forgive the brand. However, this is not simultaneous. The two factors are interdependent and self-construal. The individual decision-making process takes different weights in the decision-making process. The individual will first consider the relationship between the brand and himself, and then may make further judgments through the controllability of the damage.

\section{Self-Construal Cognitive Factors Affecting Consumer Behavior}

Different self-construals have been confirmed to have influence on many aspects of consumer behavior. The cognitive differences between independent self-construal individuals and interdependent self-construal individuals are the main factors that lead to different consumer behaviors. This section will explain how cognitive self-construal affects consumer behavior. 


\subsection{Differences in Interpersonal Understanding}

Independent self-construal is often perceived as a distinct individual with a distinct individual, while interdependent self-construal considers itself as part of a social relationship. It is a continuation of another or others are their own continuations. Reciprocal self-construal individuals pay more attention to others in social relations than independent self-construal individuals, and are more sensitive to others. This helps to create interdependent individuals, resulting in More cognitive processing to the individual's relationship to others and to others.

A study from the United States found that independent individuals consider themselves to be significantly different from others compared to the differences between themselves and others [61]. This shows that independent self-construal individuals have more sophisticated and complex knowledge of themselves. At the same time, they value themselves more independently of other people's ideas. Their decisions are more dependent on their own feelings than on the feelings of others. The self-constructed individuals are just the opposite. Their understanding of others is more elaborate and complex. They hope that they can be more similar to others. When making decisions, it always takes into account the feelings of others and social recognition. This explains the fact that independent self-construal individuals have significantly more impulse consumption and symbolic consumption behavior than reciprocal self-construal individuals.

Independent self-construal values the uniqueness of others, and therefore seek out certain goods that can demonstrate this quality. Clothing with special symbolic symbols is precisely such goods. At the same time, they do not care whether their actions are related to The harmony of society will give rise to certain opinions of others, and therefore it will not control their own bad behavior in the eyes of others. Therefore, impulsive consumption is more common in this group of people. Interdependent self-construal individuals value their relationship with others, hoping to minimize the difference between themselves and others, so their actions must be influenced by others and society. Impulse consumption has always been associated with some negative social assessments. Therefore, interdependent self-construal will reduce such behavior to achieve harmony with society, and it will not buy more novel styles in order to demonstrate its own uniqueness. The product. But why do interdependent self-construal groups spend more money on symbolic consumption-related luxury goods? We believe that it is precisely because of mutual self-construal that we value other people's opinions about ourselves and regard social connections as a kind of pressure from society. In order to allow others to have a positive view of themselves, we can better integrate into the life circle. Therefore, it will only spend some money on luxury goods.

\subsection{Situation-Dependent Differences}

In addition, there are differences in the two different self-construals in the cognition of self in other things in a particular situation. Individuals who construct 
themselves independently will not place too much emphasis on specific situations. Their principles of judgment can be separated from the diversity of situations and focus only on the core part of the problem. Interdependent self-construal individuals will be in contact with the situation, grasp the context of the whole thing, and the judgment basis is more diverse than that of the individual. Shweder and Bourne in the experiment allowed subjects from India and the United States to describe themselves as close to each other and found that the description of Indian subjects was more contextualized. Their description focused on behavior and behavior itself seemed to be more intrinsic than it was. More importantly, if they are allowed to put aside the situation and re-describe it, then the answer to be answered is a universal characteristic of human beings. There is no substantive meaning and effective information. Americans also describe specific behaviors, but this happens only when the behaviors described are too distinctive to be summarized as a trait [62]. The study by J. G. Miller also confirmed this [63]. Therefore, we believe that this can explain why different self-construal models hold different judgment standards in the face of brand damage. For an independent self-constituting consumer, the responsibility for brand damage should be borne by the company. If the damage is uncontrollable, the company should not be responsible for this, consumers will also forgive the damage event, and other Factors such as the relationship between the consumer and the brand, since such factors are not related to the damage event itself, independent self-constituting consumers will not take it into account. There are more contextual factors for the factors to be considered by interdependent self-construal individuals. Instead of always relying solely on a certain factor, they decide on which factors they rely on to make decisions based on the analysis of specific situations. First, because the cognition of interdependent self-construal is always relational, therefore, they initially considered relying on their own relationship with the brand, and then make further judgments based on the specific situation. If the damage is uncontrollable, then it is easier for them to forgive the brand.

\section{Inspiration to Practice}

By combing the literature on the effects of different self-construal on consumer behavior, we have learned that self-construal has a significant impact on consumer product choices, advertising preferences, and brand attitudes. For enterprises, how to apply the above theoretical and experimental research results to practice has important guiding significance for enterprises to improve marketing efficiency and enhance consumers' brand loyalty and identity.

Since self-construal is dynamic, it can be triggered by contextual clues and is suitable for use in various forms of advertising marketing. Based on the relationship between different products and target audiences, this paper proposes self-construal for advertising marketing practice from three perspectives. Provide inspiration. 
When the target audience of the product itself is relatively limited, the company should determine what kind of self-constitution the brand wants to output according to the target audience of the product. For example, Apple and Nike, as brands of electronic technology and sports technology, are adept at advancing the development of their respective fields with new technologies. Apple's slogan is think different, Nike's slogan is just do it. Both show a brand proposition that is not afraid of other people's eyes and strives for uniqueness. This is in line with the characteristics of young people who like to pursue new things. Therefore, both have become a favorite brand among young people.

When the target audience of some products is relatively wide and the brand image cannot be established through the established brand proposition, companies can use different slogan to promote the product in different publicity channels. For example, cereals as an easy-to-nutritive food do not have obvious characteristics in their audience. Old people, young people, office workers or housewives may all become their audiences. The elderly and housewives generally use television to learn more about goods. They generally pay more attention to family relationships. Therefore, advertising advertisements can emphasize the sharing of the whole family when television advertisements are placed. Young office workers usually pay great attention to self expression and like to shop on the Internet. Therefore, in online advertising, you can emphasize the enjoyment of being alone.

When a product has a specific target audience, and the company wants to expand the audience, because the self-construal can be primed, the enterprise can achieve the purpose of propaganda by starting the audience different from its own self-construal. For example, storytelling advertisements are used to warn independent individuals the warmth of home, or to warn the interdependent individuals the perfect to be independent.

\section{Conclusions}

This article summarizes the research literature related to my constructs in recent years, sums up the influence of self-construal on consumer behaviors, and analyzes its internal psychological mechanisms. On this basis, it proposes the inspiration for advertising marketing.

Self-construal as an individual's understanding of the relationship between themselves and others is influenced by cultural background, gender, etc. It is mainly divided into two parts: independent self-construal and interdependent self-construal. In consumer behavior, self-construal mainly affects the individual's impulsive consumer behavior and symbolic consumer behavior. Independent self-construal individuals are more likely to engage in impulsive consumption, and interdependent self-construal individuals are more likely to consume symbols. In addition, regardless of whether they are independent self-construal or dependent self-construal, individuals prefer product images that are consistent with their self-image. Interdependent individuals tend to be persuaded by 
goods and advertisements that convey collective ideas. However, since the individual has both a natural trait self-construal influenced by the cultural background and a situational self-construal that can be temporarily influenced by situational clues, brands can use advertising as a means to provide situational clues that are consistent with the image of the product. They can temporarily initiate individual self-construal of the corresponding types in order to achieve the purpose of persuading individual consumption.

This article expounds the possibility of self-construction in advertisement marketing from a theoretical perspective. There are also many cases in the real consumer environment. For example, as the SK II brand of high-end skin care products, its series of advertising changes destiny emphasizes the individual's active choice to treat their own destiny, while the L'Oreal brand of affordable skin care products emphasizes the universality of beauty in beauty for all. However, this article still lacks some empirical conclusions as a support, and future research can further prove this from an empirical perspective.

\section{References}

[1] Markus, H.R. and Kitayama, S. (1991) Culture and the Self: Implications for Cognition, Emotion, and Motivation. Psychological Review, 98, 224-253. https://doi.org/10.1037/0033-295X.98.2.224

[2] Miller, J.G. (1988) Bridging the Content-Structure Dichotomy: Culture and the Self. In: Bond, M.H., Ed., Cross-Cultural Research and Methodology Series, Vol. 11. The Cross-Cultural Challenge to Social Psychology, 266-281.

[3] Shweder, R.A. and Bourne, E.J. (1982) Does the Concept of the Person Vary Cross-Culturally? In: Marsella, A.J. and White, G., Eds., Cultural Conceptions of Mental Health and Therapy, Springer, Netherlands, 97-137. https://doi.org/10.1007/978-94-010-9220-3_4

[4] Liu, I. (1986) Chinese Cognition. In: Bond, M.H., Ed., The Psychology of the Chinese People, Oxford University Press, New York, 73-105.

[5] Brewer, M.B. and Gardner, W. (1996) Who Is This "We"? Levels of Collective Identity and Self Representations. Journal of Personality \& Social Psychology, 71, 83-93. https://doi.org/10.1037/0022-3514.71.1.83

[6] Cross, S.E., Bacon, P.L. and Morris, M.L. (2000) The Relational-Interdependent Self-Construal and Relationships. Journal of Personality \& Social Psychology, 78, 791-808. https://doi.org/10.1037/0022-3514.78.4.791

[7] Singelis, T.M. (1994) The Measurement of Independent and Interdependent Self-Construals. Personality \& Social Psychology Bulletin, 20, 580-591. https://doi.org/10.1177/0146167294205014

[8] Gudykunst, W.B. and Lee, C.M. (2003) Assessing the Validity of Self Construal Scales. Human Communication Research, 29, 253-274. https://doi.org/10.1111/j.1468-2958.2003.tb00838.x

[9] Kühnen, U. and Hannover, B. (2000) Assimilation and Contrast in Social Comparisons as a Consequence of Self-Construal Activation. European Journal of Social Psychology, 30, 799-811. https://doi.org/10.1002/1099-0992(200011/12)30:6<799::AID-EJSP16>3.0.CO;2-2

[10] Neumann, R., Steinhäuser, N. and Roeder, U.R. (2009) How Self-Construal Shapes 
Emotion: Cultural Differences in the Feeling of Pride. Social Cognition, 27, 327-337. https://doi.org/10.1521/soco.2009.27.2.327

[11] Trafimow, D., Triandis, H.C. and Goto, S.G. (1991) Some Tests of the Distinction between the Private Self and the Collective Self. Journal of Personality \& Social Psychology, 60, 649-655. https://doi.org/10.1037/0022-3514.60.5.649

[12] Zhang, Y. and Mittal, V. (2007) The Attractiveness of Enriched and Impoverished Options: Culture, Self-Construal, and Regulatory Focus. Personality \& Social Psychology Bulletin, 33, 588. https://doi.org/10.1177/0146167206296954

[13] Howard, E.S., Gardner, W.L. and Thompson, L. (2016) The Role of the Self-Concept and the Social Context in Determining the Behavior of Power Holders: Self-Construal in Intergroup Versus Dyadic Dispute Resolution Negotiations. Journal of Personality \& Social Psychology, 93, 614-631.

https://doi.org/10.1037/0022-3514.93.4.614

[14] Lee, A.Y., Aaker, J.L. and Gardner, W.L. (2000) The Pleasures and Pains of Distinct Self-Construals: The Role of Interdependence in Regulatory Focus. Journal of Personality \& Social Psychology, 78, 1122. https://doi.org/10.1037/0022-3514.78.6.1122

[15] Gaertner, L., Sedikides, C. and Graetz, K. (1999) In Search of Self-Definition: Motivational Primacy of the Individual Self, Motivational Primacy of the Collective Self, or Contextual Primacy? Journal of Personality \& Social Psychology, 76, 5-18. https://doi.org/10.1037/0022-3514.76.1.5

[16] Stapel, D.A. and Ki, V.D.Z. (2006) The Self Salience Model of Other-to-Self Effects: Integrating Principles of Self-Enhancement, Complementarity, and Imitation. Journal of Personality \& Social Psychology, 90, 258-271. https://doi.org/10.1037/0022-3514.90.2.258

[17] Cheng, R.W. and Lam, S.F. (2007) Self-Construal and Social Comparison Effects. British Journal of Educational Psychology, 77, 197.

[18] Kühnen, U. and Oyserman, D. (2002) Thinking about the Self Influences Thinking in General: Cognitive Consequences of Salient Self-Concept. Journal of Experimental Social Psychology, 38, 492-499. https://doi.org/10.1016/S0022-1031(02)00011-2

[19] Krishna, A., Zhou, R. and Zhang, S. (2008) The Effect of Self-Construal on Spatial Judgments. Journal of Consumer Research, 35, 337-348. https://doi.org/10.1086/588686

[20] Gardner, W.L., Gabriel, S. and Hochschild, L. (2002) When You and I Are "We," You Are Not Threatening: The Role of Self-Expansion in Social Comparison. Journal of Personality \& Social Psychology, 82, 239. https://doi.org/10.1037/0022-3514.82.2.239

[21] Holland, R.W., Roeder, U.R., van Baaren, R.B., Brandt, A.C. and Hannover, B. (2004) Don't Stand So Close to Me: The Effects of Self-Construal in Interpersonal Closeness. Psychological Science, 15, 237-242. https://doi.org/10.1111/j.0956-7976.2004.00658.x

[22] van Baaren, R.B., Maddux, W.W., Chartrand, T.L., De, B.C. and Van, K.A. (2003) It Takes Two to Mimic: Behavioral Consequences of Self-Construals. Journal of Personality \& Social Psychology, 84, 1093-1102. https://doi.org/10.1037/0022-3514.84.5.1093

[23] Pöhlmann, C., Carranza, E., Hannover, B. and Iyengar, S.S. (2007) Repercussions of Self-Construal for Self-Relevant and Other-Relevant Choice. Social Cognition, 25, 284-305. https://doi.org/10.1521/soco.2007.25.2.284

[24] Rook, D.W. (1987) The Buying Impulse. Journal of Consumer Research, 14, 189-199. https://doi.org/10.1086/209105 
[25] Rook, D.W. and Fisher, R.J. (1995) Normative Influences on Impulsive Buying Behavior. Journal of Consumer Research, 22, 305-313. https://doi.org/10.1086/209452

[26] Hoch, S.J. and Loewenstein, G.F. (1991) Time-Inconsistent Preferences and Consumer Self-Control. Journal of Consumer Research, 17, 492-507. https://doi.org/10.1086/208573

[27] Vohs, K.D. and Faber, R.J. (2007) Spent Resources: Self-Regulatory Resource Availability Affects Impulse Buying. Journal of Consumer Research, 33, 537-547. https://doi.org/10.1086/510228

[28] Zhang, Y. and Shrum, L.J. (2008) The Influence of Self-Construal on Impulsive Consumption. Journal of Consumer Research, 35, 838-850. https://doi.org/10.1086/593687

[29] Kacen, J.J. and Lee, A.J.A. (2002) The Influence of Culture on Consumer Impulsive Buying Behavior. Journal of Consumer Psychology, 12, 163-176. https://doi.org/10.1207/S15327663JCP1202_08

[30] Castro, J.M.D. (1994) Family and Friends Produce Greater Social Facilitation of Food Intake than Other Companions. Physiology \& Behavior, 56, 445.

https://doi.org/10.1016/0031-9384(94)90286-0

[31] Luo, X. (2005) How Does Shopping with Others Influence Impulsive Purchasing? Journal of Consumer Psychology, 15, 288-294. https://doi.org/10.1207/s15327663jcp1504_3

[32] Elliott, R. (2013) Existential Consumption and Irrational Desire. European Journal of Marketing, 31, 285-296. https://doi.org/10.1108/03090569710162371

[33] Lee, J.A. and Kacen, J.J. (2000) The Relationship between Independent and Interdependent Self-Concepts and Reasons for Purchase. Journal of Euromarketing, 8, 83-99. https://doi.org/10.1300/J037v08n01_06

[34] Kim, H.S. and Drolet, A. (2003) Choice and Self-Expression: A Cultural Analysis of Variety-Seeking. Journal of Personality and Social Psychology, 85, 373. https://doi.org/10.1037/0022-3514.85.2.373

[35] Herrmann, A. and Heitmann, M. (2006) Providing More or Providing Less? Accounting for Cultural Differences in Consumers Preference for Variety. International Marketing Review, 23, 7-24. https://doi.org/10.1108/02651330610646278

[36] Tepper, K. and Hoyle, R.H. (1996) Latent Variable Models of Need for Uniqueness. Multivariate Behavioral Research, 31, 467. https://doi.org/10.1207/s15327906mbr3104_4

[37] Clark, R.A., Zboja, J.J. and Goldsmith, R.E. (2007) Status Consumption and Role-Relaxed Consumption: A Tale of Two Retail Consumers. Journal of Retailing and Consumer Services, 14, 45-59. https://doi.org/10.1016/j.jretconser.2006.03.003

[38] Millan, E. and Reynolds, J. (2011) Independent and Interdependent Self-Views and Their Influence on Clothing Consumption. International Journal of Retail and Distribution Management, 39, 162-182. https://doi.org/10.1108/09590551111115015

[39] Kastanakis, M.N. and Balabanis, G. (2012) Between the Mass and the Class: Antecedents of the "Bandwagon" Luxury Consumption Behavior. Journal of Business Research, 65, 1399-1407. https://doi.org/10.1016/j.jbusres.2011.10.005

[40] Wong, N.Y. and Ahuvia, A.C. (1998) Personal Taste and Family Face: Luxury Consumption in Confucian and Western Societies. Psychology and Marketing, 15, 423-441.

https://doi.org/10.1002/(SICI)1520-6793(199808)15:5<423::AID-MAR2>3.0.CO;2-9

[41] Millan, E. and Reynolds, J. (2014) Self-Construals, Symbolic and Hedonic Prefe- 
rences, and Actual Purchase Behavior. Journal of Retailing and Consumer Services, 21, 550-560. https://doi.org/10.1016/j.jretconser.2014.03.012

[42] Han, S. and Shavitt, S. (2015) Persuasion and Culture: Advertising Appeals in Individualistic and Collectivistic Societies. Journal of Experimental Social Psychology, 30, 326-350. https://doi.org/10.1006/jesp.1994.1016

[43] Zhang, Y. and Gelb, B.D. (1996) Matching Advertising Appeals to Culture: The Influence of Products' Use Conditions. Journal of Advertising, 25, 29-46. https://doi.org/10.1080/00913367.1996.10673505

[44] Sirgy, M.J. (1982) Self-Concept in Consumer Behavior: A Critical Review. Journal of Consumer Research, 9, 287-300.

[45] Hong, J.W. and Zinkhan, G.M. (1995) Self-Concept and Advertising Effectiveness: the Influence of Congruency, Conspicuousness, and Response Mode. Psychology and Marketing, 12, 53-77. https://doi.org/10.1002/mar.4220120105

[46] Wang, C.L. and Mowen, J.C. (1997) The Separateness-Connectedness Self-Schema: Scale Development and Application to Message Construction. Psychology and Marketing, 14, 185-207. https://doi.org/10.1002/(SICI)1520-6793(199703)14:2<185::AID-MAR5>3.0.CO;2-9

[47] Keller, P.A. and Block, L.G. (1997) Vividness Effects: A Resource-Matching Perspective. Journal of Consumer Research, 24, 295-304. https://doi.org/10.1086/209511

[48] Krishnamurthy, P. and Sujan, M. (2004) Retrospection versus Anticipation: The Role of the Ad under Retrospective and Anticipatory Self-Referencing. Journal of Consumer Research, 26, 55-69. https://doi.org/10.1086/209550

[49] Anderson, C.A. (1983) Imagination and Expectation: The Effect of Imagining Behavioral Scripts on Personal Influences. Journal of Personality and Social Psychology, 45, 293-305. https://doi.org/10.1037/0022-3514.45.2.293

[50] Gregory, W.L., Cialdini, R.B. and Carpenter, K.M. (1982) Self-Relevant Scenarios as Mediators of Likelihood Estimates and Compliance: Does Imagining Make It So? Journal of Personality and Social Psychology, 43, 89-99. https://doi.org/10.1037/0022-3514.43.1.89

[51] Petrova, P.K. and Cialdini, R.B. (2005) Fluency of Consumption Imagery and the Backfire Effects of Imagery Appeals. Journal of Consumer Research, 32, 442-452. https://doi.org/10.1086/497556

[52] Aaker, J., Fournier, S. and Brasel, S.A. (2004) When Good Brands Do Bad. Journal of Consumer Research, 31, 1-16. https://doi.org/10.1086/383419

[53] Folkes, V.S. (1984) Consumer Reactions to Product Failure: An Attributional Approach. Journal of Consumer Research, 10, 398-409. https://doi.org/10.1086/208978

[54] Klein, J. and Dawar, N. (2004) Corporate Social Responsibility and Consumers' Attributions and Brand Evaluations in a Product-Harm Crisis. International Journal of Research in Marketing, 21, 203-217. https://doi.org/10.1016/j.ijresmar.2003.12.003

[55] Ahluwalia, R., Burnkrant, R.E. and Unnava, H.R. (2000) Consumer Response to Negative Publicity: The Moderating Role of Commitment. Journal of Marketing Research, 37, 203-214. https://doi.org/10.1509/jmkr.37.2.203.18734

[56] Tax, S., Brown, S.W. and Chandrashekaran, M. (1998) Customer Evaluations of Service Complaint Experiences: Implications for Relationship Marketing. Journal of Marketing, 60, 60-76. https://doi.org/10.2307/1252161

[57] Cross, S.E. and Madson, L. (1997) Models of the Self: Self-Construals and Gender. Psychological Bulletin, 122, 5-37. https://doi.org/10.1037/0033-2909.122.1.5 
[58] Ho, M.Y. and Fung, H.H. (2011) A Dynamic Process Model of Forgiveness: A Cross-Cultural Perspective. Review of General Psychology, 15, 77-84. https://doi.org/10.1037/a0022605

[59] Takaku, S., Weiner, B. and Ohbuchi, K.I. (2001) A Cross-Cultural Examination of the Effects of Apology and Perspective Taking on Forgiveness. Journal of Language and Social Psychology, 20, 144-166. https://doi.org/10.1177/0261927X01020001007

[60] Sinha, J. and Lu, F.C. (2016) "I" Value Justice, But "We" Value Relationships: Self-Construal Effects on Post-Transgression Consumer Forgiveness. Journal of Consumer Psychology, 26, 265-274. https://doi.org/10.1016/j.jcps.2015.06.002

[61] Holyoak, K.J. and Gordon, P.C. (1983) Social Reference Points. Journal of Personality and Social Psychology, 44, 881-887. https://doi.org/10.1037/0022-3514.44.5.881

[62] Shweder, R.A. and LeVine, R.A. (1984) Culture Theory: Essays on Mind, Self, and Emotion. Cambridge University Press, Cambridge.

[63] Miller, J.G. (1984) Culture and the Development of Everyday Social Explanation. Journal of Personality and Social Psychology, 46, 961-978.

https://doi.org/10.1037/0022-3514.46.5.961 